\title{
IMAge of Flesh/Flesh of The IMAge: The Flayed Figure IN HenRi DE MONDEville's ChIRURGIA
}

\author{
Lauren Rozenberg
}

The fourth, a flayed man carrying his skin over his shoulders on a stick, and the skin of his head with hair, the skin of his hands, and his feet, and the lacerated flesh that is on the body, and the white which is the breasts and the emunctories [excretory organs], and by the opening of the venter [belly] is the fat and the lard. ${ }^{1}$

human body, or what is left of it, walks into and disrupts these lines
in a fourteenth-century copy of Henri de Mondeville's Chirurgia
(figure I), now bound in a medical miscellany in Trinity College Cambridge (MS O.2.44). ${ }^{2}$ The fourth pen-drawn figure of the anatomical treatise carves its own space into the textual apparatus of the page, its left hand folded onto the chest, and the skin that was once one with the adjacent body dangling from the staff on its shoulder. The caption quoted above describes this as a flayed figure carrying its own skin and showcasing what remains of the body: the underlying adipose, fleshy and fatty tissues.

The flayed figure and the anatomical description that accompanies it are first and foremost concerned with flesh, as is this article. My analysis begins by tracing how flesh was apprehended at the time, and specifically, by Mondeville, to reflect on the relationship between flesh and the Cambridge flayed figure as an image situated at the emergence of anatomy as a discipline. Flesh is arguably at the core of how Christian piety is experienced, especially after the Fourth Lateran Council, which established the doctrine of transubstantiation. ${ }^{3}$ It is said in Genesis that God created mankind in his image, according to his likeness (Gen I:26). The fourteenth-century mystic Jan van Ruysbroeck (ca. I293-I38I) stated in the Mirror of Eternal Salvation that 'his image is his son [...]. It is in reference to this eternal image that we have all been created. It is to be found essentially and personally in all men'. ${ }^{4}$ 


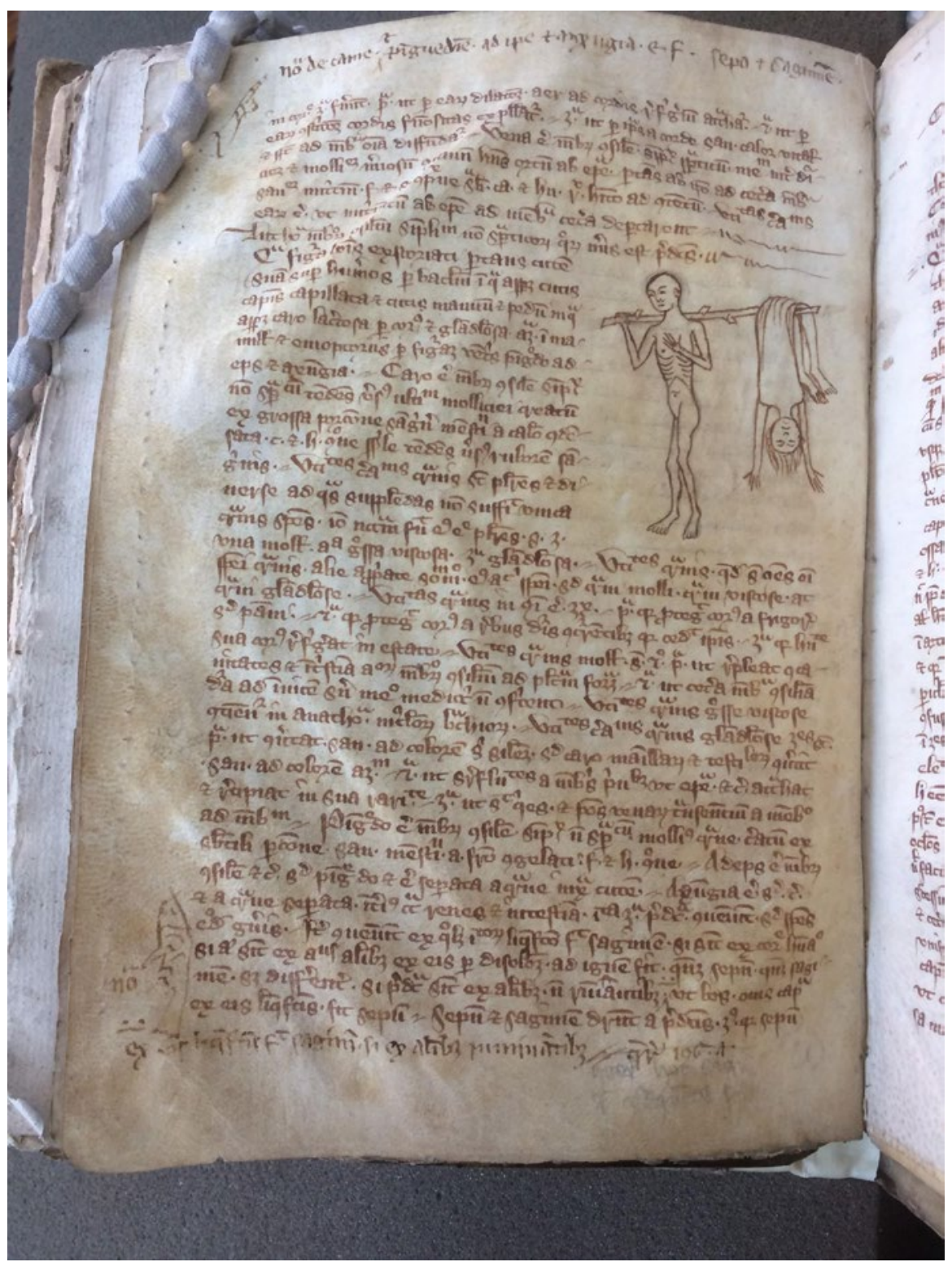

Figure I Anonymous, folio $4 v$, fourteenth century. Ink on parchment, $20,3 \mathrm{~cm} \mathrm{x} \mathrm{I3}, 8 \mathrm{~cm}$. Trinity College Cambridge, MS O.2.44. CCourtesy of the Master and Fellows of Trinity College Cambridge. Photo: Lauren Rozenberg. 
Christ, the perfect image of his father, had been incarnated, made flesh. By laying bare this context, this article seeks to come to terms with the fleshiness of the medieval image, and the way it was received by beholders.

Suzannah Biernoff has shown how research on medieval visuality benefits from a phenomenological approach, such as the writings of Maurice Merleau-Ponty, especially in regard to the role played by flesh in forging the relationship between subjectivity and embodiment. ${ }^{5}$ Building on her work, I place Merleau-Ponty's ontology of flesh into dialogue with medieval understandings of flesh present in the Cambridge drawing. ${ }^{6}$ Merleau-Ponty posits an association between flesh and the visual. In his later work on 'indirect ontology', Merleau-Ponty equates flesh with visibility itself: '[i]t is this Visibility, this generality of the Sensible in itself, this anonymity innate to Myself that we have previously called flesh, and one knows there is no name in traditional philosophy to designate it'. ${ }^{7}$ Merleau-Ponty further develops the concept of 'common flesh', a phenomenon where sensing and sensed intertwine and become one. Visibility relates therefore to the Sensible, the world of sensation.

This article, however, aims to go beyond equating flesh and visibility. Given the interchange of medium and image at play, it argues that the figure represented on folio $4 \mathrm{v}$ of Trinity O.2.44 is not simply a representation of flesh, but that the parchment becomes the very flesh of the image itself. I contend that, in addition to picturing an embodied likeness composed of different layers of skin, flesh and fat, the drawing constructs a visual discourse on flesh connected to the act of seeing the body.

\section{Mondeville and the image}

Henri de Mondeville (I260 - I320) was a French royal surgeon for Philip IV the Fair (I268 - I3 I4) and Louis X (I289- I3 I6). He taught surgery and anatomy at the University of Montpellier until approximately I 304 , before settling in Paris where he composed his Chirurgia. ${ }^{8}$ One of his students, the famous surgeon Guy de Chauliac (ca. I300 - I368), mentions that in I304, Mondeville taught anatomy at Montpellier with the help of thirteen illustrations, none of which has survived. ${ }^{9}$ Nonetheless, Chauliac's report testifies to a new conception of anatomy. The flayed figure is part of this emerging new anatomical imagery. The opening lines of the first treatise in Mondeville's Chirurgia state that it is based on a lecture given by the surgeon 
in Paris in I306 (Anno post incarnacionem christi millesimo trescentesimo sexto). Despite containing illustrations not found in other copies, the Cambridge manuscript has received far less scholarly attention than other versions of the text. ${ }^{10}$ Although a discussion of the entirety of the anatomical text is beyond the scope of this article, the Cambridge flayed figure presents an opportunity to think through the ways in which a late medieval lay audience could engage with medical images.

The Cambridge text is written in cursive anglicana, a script characteristic of English manuscripts of the late Middle Ages, which suggests that the treatise was copied in England or by an English scribe. The I 306 Parisian lecture provides a terminus post quem for the making of the manuscript. The drawings further suggest that it was made in the first quarter of the fourteenth century, probably no later than I325. No evidence indicates for whom the manuscript was made. The few glosses suggest that at least one reader commented on its content, perhaps a medical practitioner, a student or an educated person interested in medicine. Indeed, in the early fourteenth century, lay audiences became increasingly interested in topics such as anatomy and began to collect medical treatises. Moreover, this was a period in which there was an increased interest in private devotional practices focusing on Christ's body, blood and flesh. ${ }^{11}$ Significantly, the images in Trinity O.2.44 were made at a time when teaching on the body and the discipline of surgery were evolving. In the late eleventh and twelfth centuries, through the influence of the School of Salerno, new surgical treatises were produced in Italy, prompting a resurgence in the profession. Western medical teaching was also radically transformed in the twelfth century when Arabic works, such as Avicenna's Canon, were circulated. In Mondeville's time, there were three types of medical practitioners: physicians, surgeons and barbers. MarieChristine Pouchelle, in the most important contribution on Mondeville to date, exposes the conflict between surgeons and physicians and analyses Mondeville's desire to raise surgery from the rank of a manual profession to that of a noble art. ${ }^{12}$ The images used by Mondeville in the I304 lecture at Montpellier, which Loren MacKinney suggests were in direct continuity with thirteenth-century tradition, might reflect this will to differentiate and elevate surgery, by using visual aids to improve teaching. ${ }^{13}$ Monica Green estimates that only a quarter to a third of surgical texts were illustrated. ${ }^{14}$ She explains: 'Visualization was not unimportant, but it happened more in the 
mind's eye than one on the page of a book' ${ }^{15}$ Lavishly illustrated treatises tended to be made for upper-class citizens with an epistemological interest rather than for medical practitioners.

Images, and therefore anatomical representations, participate within an ontology of visibility; they are part of a system of representation that is closely tied to notions of embodiment. Hans Belting writes that 'the human being is the natural locus of images, a living organ for images, as it were. ${ }^{16}$ It is inside the body that images are felt and dealt with. He also suggests that image and medium are contingent and that a 'picture is the image with a medium'. ${ }^{17}$ Building on Belting's argument, the locus or medium of this image can be thought of as parchment, a different type of body. Also, this medium and image can be considered as coming together to form a visible sign rather than a picture, an argument more in keeping with medieval theories of visibility. The theologian Hugh of Saint Victor (ca. I096-I I4I) defines visibility as a divine phenomenon:

For this whole visible world is a book written by the finger of God, that is, created by divine power; and individual creatures are as figures therein not devised by human will but instituted by divine authority to show forth the wisdom of the invisible things of God. ${ }^{18}$

Human figures are therefore the visible sign of God's invisible power within the book of nature, the visible world. This passage from Hugh's De tribus diebus summarising the conception of the world as a book of nature was re-used throughout the following centuries. Nature was seen as an open book from which knowledge, especially divine knowledge, could be gained. Understanding could be obtained through everything that was visible. In Eye and Mind (196I), his last published essay, Merleau-Ponty offers an understanding of flesh as both finite and infinite. ${ }^{19}$ This echoes the medieval conception of Christ's dual nature. Christ, who was made flesh (John I:I4), is simultaneously mortal, therefore finite, and divine, thus infinite. In the Cambridge flayed figure, the skin that protects the flesh, and through which sensation passes, is finite; it connotes the act of flaying and therefore death. But the walking, fleshy body is itself infinite. Precisely because it is a representation, the figure is outside of life and death because it now extends into a different category of visuality, namely — that of the image. 


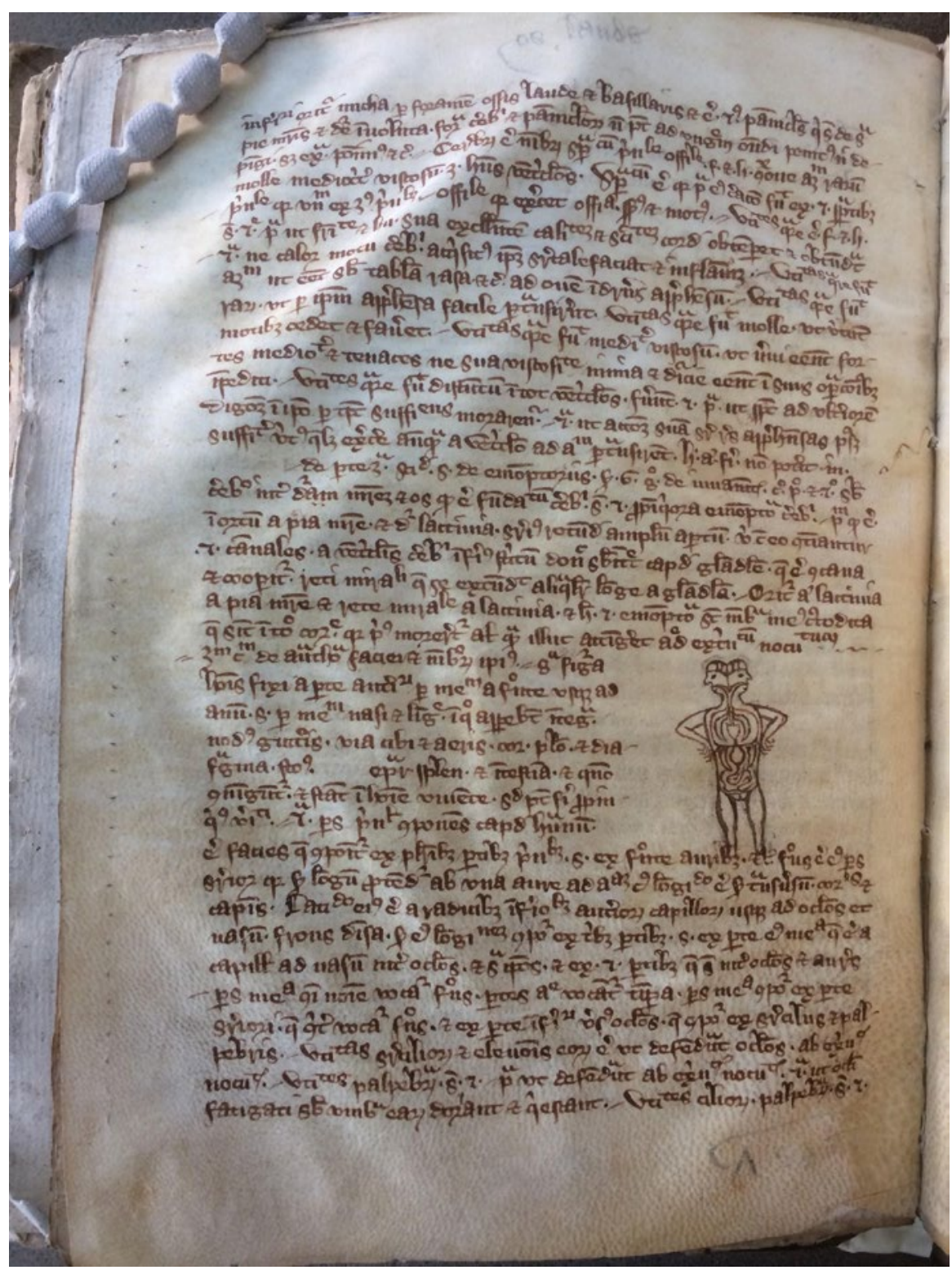

Figure 2 Anonymous, folio $7 v$, fourteenth century. Ink on parchment. Trinity College Cambridge, MS O.2.44. CCourtesy of the Master and Fellows of Trinity College Cambridge. Photo: Lauren Rozenberg. 
As discussed earlier, Jan van Ruysbroeck explains that mankind has been created in the likeness of God and, thus, that God's image can be found in every human. Later on, the mystic states that all humans are actually united in this eternal divine image that provides life and creation itself. ${ }^{20}$ Humans are part of this divine system of visuality. They 'are as figures', and Christ has been incarnated as the image of his father for the sake of these humans. All are thus part of the same visible system that is built on the intermingling of flesh and images. This arguably corresponds to Merleau-Ponty's own conception of the 'common flesh'. In the context of Mondeville's Chirurgia, what is being sought is a different type of knowledge than theology. Nonetheless, visuality was conceptualised as always being in a relationship with the invisible, as putting the visible and the invisible into dialogue. In the flayed figure in Trinity O.2.44, the human body becomes the measure of the comparison and replaces the divine. The figure in this material book of knowledge, or Book of Nature, is the visible sign of what is inside or outside the human body. We see this on folio I $3 \mathrm{~V}$ of the treatise, which depicts a bisected figure standing on two legs with its head cut in two, folded open, and its abdomen cut (figure 2). What holds the body in this liminal state of being whole and divided, of representing what is inside (the head and abdomen) and what is outside (the integrity of the legs), is the flesh.

Mondeville's use of visual aids to theorise the body, within this system of representation, posits an understanding based on visibility and experience. For example, he writes that to sensibly demonstrate the anatomy of the skull, one must use a real skull, with certain features such as serrations, but also something to mimic hair, skin and flesh. The emphasis on seeing the body and its parts such as flesh is demonstrated by the abundance of images in the Cambridge manuscript, but also in the images themselves. On fol. 9r, (figure 3) an eye comes out of the text to capture the viewer's gaze and directly confront them with the recognition of their own eye as it scans the page. Also, the fact that Mondeville is very often depicted as a teacher holding a skull in front of a class demonstrates the importance of visuality in his teaching through the vehicle of representation. The representation of flesh is the materialisation of this process of visibility.

Another striking aspect of the drawing is the absence of colour. Discussing the illumination in another copy of the treatise, Bibliothèque nationale de France (BnF), MS français 2030, Jack Hartnell states that 'exposing the 


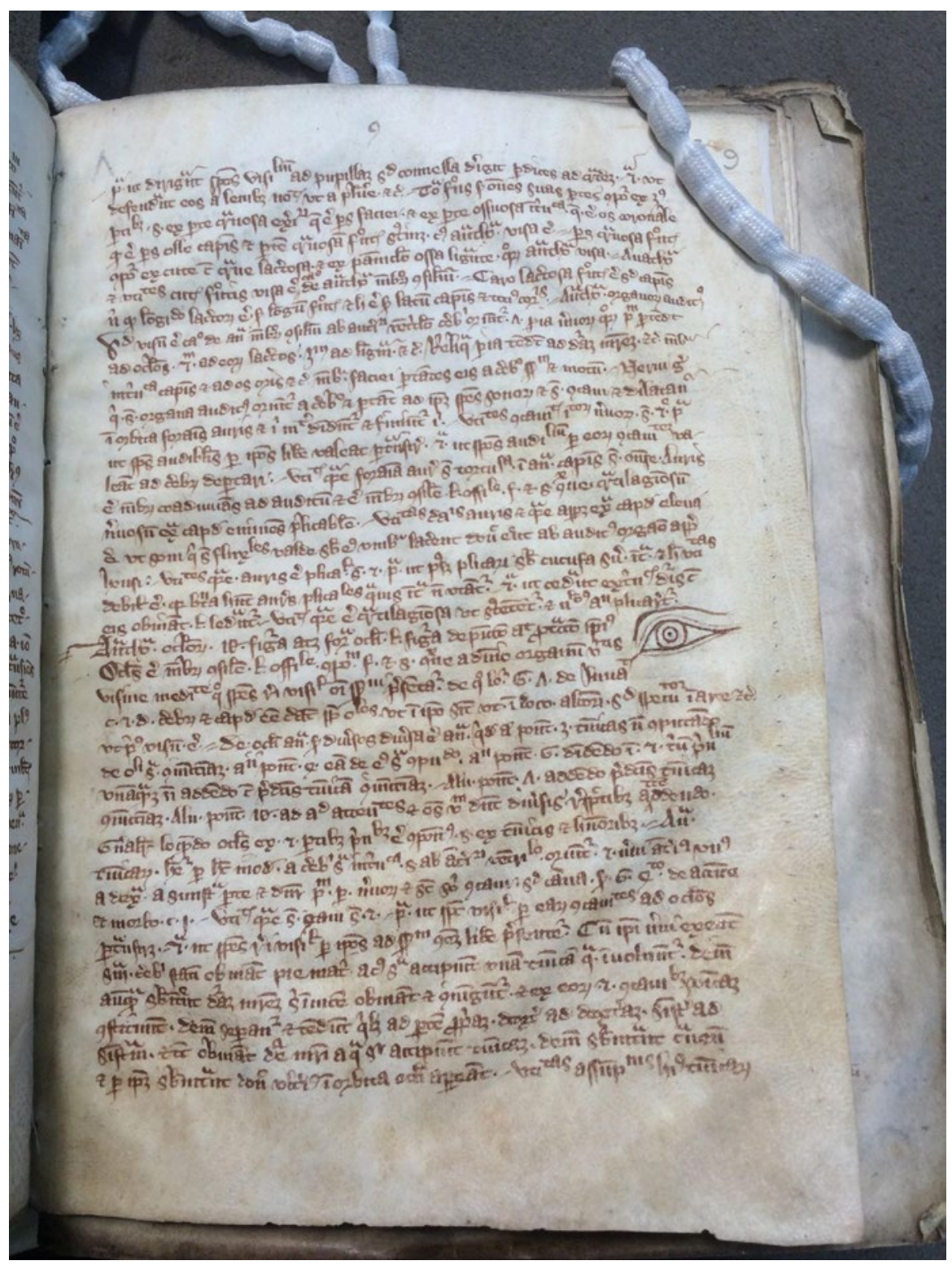

Figure 3 Anonymous, folio gr, fourteenth century. Ink on parchment. Trinity College Cambridge, MS O.2.44. CCourtesy of the Master and Fellows of Trinity College Cambridge. Photo: Lauren Rozenberg. 
whitish hue of the subcutaneous fat that lies under the body's outer layers, the depiction of the flayed figure outside his skin is deliberately revelatory, displaying the subtle gradations of colour and texture found in the body beneath'. ${ }^{21}$ Indeed, in the BnF copy, the colours make the image stand on its own on the page. In a different manner, the pen drawing in the Cambridge copy assimilates the representation to the text, a dynamic reinforced by the movement of the figure also walking into the text (figure I). The drawing in $\mathrm{BnF}$ français 2030 is concerned with repulsion, the other (in Trinity O.2.44) emphasises assimilation. The absence of paint, of pigments, does not, however, mean that the Cambridge figure is not coloured. On the contrary, it has one very notable colour: that of the parchment, of flayed skin. This colour is marked by the absence of the sanguine flesh that was once attached to this skin, which expelled and absorbed fluids through it. As such, the reality of the drawing is even more important in Trinity O.2.44 than is the case with the $\mathrm{BnF}$ français 2030 figure, where paint makes the image stand out from page and text, and disassociates the representation of the flesh from its material support. The colours distinguish the latter against the page, while conversely the figure in the Cambridge copy (figure I) is located within the page, the final element that makes the image the 'flesh of things', and not simply an image of flesh.

\section{Henry de Mondeville and medieval flesh}

The act of flaying is not directly the subject of the figure. What the drawing illustrates is the exhibition of flesh and fat - precisely what has been removed from the flayed animal to create the parchment support for the image. The skin hanging so fluidly at the extremity of the stick seems as if it is on the verge of falling, of disappearing from the image itself. There is also an ambivalence between the exhibition of flesh and the disappearance of skin as they work together to constitute the body. One needs the other, and flaying is the only means of visualising what is under the skin. The image focuses on what remains of the body, which the figure points to with its left hand: flesh, fat and lard. ${ }^{22}$ I make this distinction between skin and flesh not only because when this illustration is discussed, it is always in terms of skin, but also because skin and flesh are distinct entities in medieval medical surgical theory. Influenced by classical Greek and Arabic medicine, especially the Galenic system conveyed in the work of Avicenna, the body was thought to 
be composed of four humours: yellow bile, phlegm, black bile and blood. A healthy body meant balanced humours. Organs and members of the body governed by these humours were created at the embryo stage from either maternal menstrual blood or paternal sperm. The relationship between the Cambridge flayed figure and visuality that I turn to later in this article is based on these morphological conceptions.

In Mondeville's Chirurgia, the difference between skin and flesh is made explicit by the language he uses to caption the figure. The figure carries its skin (cutem) which displays the skin of the head and hands (cutis), but on the figure, it is the flesh (caro) that is displayed. Cutis is the traditional Latin word used to describe the skin. It also serves as a metaphor for leather or the idea of covering something. ${ }^{23}$ Caro designates animal flesh because it is the part that can be removed and consumed. It is also the seat of human passions. The duality between flesh and skin reinforces their connection and the building up of the body in various layers: skin itself is also made of several layers (the outer one or skin proper, and the inner one or panicle), and flesh and fat come together to add to this protective barrier. The description of flesh (caro) is followed by fat (pinguedo) and adipose panicle (adeps). The anatomical description of skin will only come in later in relation to the next figure. There is, therefore, an internal tension: the caption accentuates the skin, whereas the image first brings to mind the act of flaying and the anatomical description focuses on flesh.

Flesh - as well as bones and nerves - is defined by Mondeville as a 'similar simple non spermatic member'. ${ }^{24}$ In medieval anatomy, consimile (similar) is a specific term that means it is a part of something else (like the hand is part of the arm) and simply refers to how it is not composed of other substances (by contrast, tendons are composed of both nerves and ligaments). ${ }^{25}$ Seeing the figure next to the morphological explanation of flesh, the medieval reader would get a sense that, as an effect of translation, the flesh in the illustration is also consimile, i.e. it is part of the parchment of the page, part of the manuscript's physicality. The tension between cutis and caro is partially resolved: as consimile, they complete each other, and because cutis comes after caro, skin is an extension of flesh. They are different, but not separate. Flesh is a non-spermatic member, which means it was not formed from the fertiliser sperm but from the mother's menstrual blood. Skin, on the other hand, is a spermatic member. This difference entails that flesh is actually sanguine 
according to humoral theory; it is renewable but also clearly distinct from the body.

Additionally, Mondeville explains that there are three varieties of flesh in each human body: a flabby, a rough and a glandular one. They have three functions: firstly, flesh protects the body from the cold like a piece of clothing. Secondly, it protects the body from shocks. Thirdly, because it is humid, flesh can keep the body fresh when the temperature rises. The flabby flesh fills in the void of other members and protects the hard consimile members from friction. The glandular flesh has the following functions: it brings colour to blood, attracts the superfluity of other members, stocks it, and allows the veins to rest upon it. Such a description should prompt readers to further reflect on the presence of the image, which also fills a void on the page but is devoid of colours, as if the image has been phlebotomised.

Guy de Chauliac summarises these views on flesh more clearly in the second chapter of his own manual on surgery. There he approaches the body as a layered object. Chauliac begins with skin, the external envelope of the body and internal organs, which he calls the panicle. Next comes the fat, which lubricates the different internal parts of the body. When it is situated right under the skin, it is simply named 'fat', but when it is within the organ, it is called 'lard'. Finally, Chauliac deals with the three types of flesh:

The simplest is pink as found in the glans penis and in the gums around the teeth. Another type is glandular or nodose, as is found in the testicles, the breasts, and the emunctories. The third type of flesh is in muscles or lacerti [tendons]; a large amount of it is distributed throughout the body; it is responsible for voluntary and involuntary (i.e. manifest) movements. ${ }^{26}$

Mondeville is less clear on this point, lingering more on the causes and form of flesh. He starts with the various types of flesh, then moves on to the fat, before turning to the panicle and the lard, all of which are distinguished from the flesh and look alike. ${ }^{27}$ What Mondeville's description lacks in clarity, it makes up for with the figure illustrating the passage. The drawing penetrates the text to reinforce it. The fleshy figure and written language are in the process of assimilating one another. The image is, like the flesh it displays, consimile. Flesh is responsible for the movements of the body and moves the 
image toward the text. Additionally, another fleshy incorporation opens onto another level, that of representation itself.

\section{Fleshing out the drawing}

Lanfranc of Milan (ca. I250-I306), another contemporary of Mondeville whose Chirurgia Magna was composed around 1296 in France, differentiates the same three types of flesh as Mondeville. However, Lanfranc also states that the function of the simple flesh is to fill in voids and reform the shapes of wounds. ${ }^{28}$ Katie L. Walter calls this crucial idea of flesh as capable of filling a void 'incarnatyf medicine. ${ }^{29}$ Walter posits that 'incarnatyf medicine - the art of making flesh in the Middle English tradition - was a surgical practice in late medieval England, which drew on the substitutive properties attributed to flesh. She concludes that in 'incarnatyf medicine, 'flesh emerges as radically different from the body and thus as capable of supplementing, or substituting for, its parts' ${ }^{30}$ Furthermore, she contends that flesh should be considered as a prosthesis because it is envisioned as replacing something absent. Because it is sanguine and non-spermatic, flesh can take the place of skin, which because it is a spermatic member, cannot be replaced once it is lost. If flesh can, therefore, be considered an element of substitution supplementing a body part, what about representations of flesh inscribed on a body part such as parchment? Does the image participate in this fluid dynamic of filling and replacing? Does the image that comes to be located in the void next to the text become a sort of flesh? Is it part of the skin of the manuscript or, like flesh, is it another substance under the skin, the image acting as an additional layer of meaning on the page? Attention to the parchment, its layout and the drawing itself can answer these questions.

Parchment, as animal skin, is made through a process of transformation that starts with an act of skinning, much like the one represented by the Cambridge flayed figure. Mondeville himself refers to furriers several times in his Chirurgia. For example, in the second treatise, he advises that, in the treatment of sores and wounds,

[...] someone will strongly bring closer the lips of the wound, and will slowly present them to the surgeon who, with a big needle and a strong thread, will suture them deeply with close stitches, just as furriers sew skins [...] If blood massively flows from the wound, it will be closed in the same manner, except that in this case we ought to do a suture just as furriers sew skins. ${ }^{31}$ 
Surgeons are encouraged to work with skin in similar ways to furriers. The surgical act is, therefore, deeply entrenched in the notion of sanguine and fleshy skin. The imagery that parchment conveys is not simply related to the medium's general significance in medieval culture, but specific to this anatomical work. Everything on the page of the Cambridge flayed figure has been physically or metaphorically mutilated. An animal gave its life, and lost its hair, flesh and fat, to be transformed into parchment; the parchment is pierced once again when it is written upon and bound. The two marginal figures depicted on the page, are disembodied body parts. The flayed figure remains in a liminal place, whereby it has been flayed like the animal but still clenches to its bodily materiality. It is still incarnated.

Furthermore, the text is abbreviated. The reading experience is constantly riddled with cuts, visual marks that point toward something that has been made invisible and that is brought back to the realm of the visible by the exchange between viewer and page. Hugh of Saint Victor defines reading as the act of dividing, which allows reason to distinguish between the universal and the particular. In this schema, in order to learn through reading, one should start with the generality and further divide it into parts. ${ }^{32}$ This method is the precise one adopted by Mondeville in his Chirurgia, where he starts by defining all the members of the body, such as flesh. Moreover, he defines anatomy as 'the exact division of the human body as well as its members and parts'. ${ }^{33}$ As such, Mondeville understands anatomy in the same terms as Hugh of Saint Victor theorises the reading process. Anatomy is conceived as a process of reading the body. The sense that text and image merge reinforces this aspect of the illustration. The image is designed to be 'read' with the eyes. Alongside the Cambridge flayed figure, words have therefore also been effectively flayed, deprived of a part of their bodily entity. The depth of bodies and words is hidden, flattened on the surface, and only rendered visible onto the page through bodily recognition and reading.

The drawing constitutes a representation of flesh only once it is recognised as such by the viewer. In turn, the image becomes flesh in such a way that it fills a void and merges with the skin. By extension, the anatomical illustrations in Mondeville's Chirurgia only fully represent parts of the body when they are compared by the beholders with their own corresponding body parts. The image exists in the fleshy exchange between the parchment page and 
the reader's own body. Undoubtedly, the flayed skin hanging from the stick recalls the creation of the page itself. However, the subject of the image is not the hanging skin, but the flesh that remains on the walking body. Therefore, if skin and page are so clearly associated, what is the role of flesh? I contend that flesh relates to the image on the page, as well as to the action of seeing the body and the image itself.

\section{Fleshy chiasm and movement}

Merleau-Ponty develops what he calls the 'chiasm', building upon the rhetorical figure of the chiasmus, a crossing of similar elements within a sentence, which establishes parallels. Merleau-Ponty further defines his notion of chiasm in relation to flesh, as a mediating structure involving reciprocity: while the body is touching itself, it becomes both sentient and sensible. ${ }^{34}$ This resonates particularly well with the Cambridge flayed figure. When the reader touches the parchment skin and sees an image of flesh, they become aware of their own flesh. They see themselves in this figure because, in its reciprocity, the chiasm creates a 'common flesh' of things, when sensed and sensing intertwine. The chiasm does not simply reverse the dynamic of the drawing, it also plays upon the similarities and differences between the animal and human skins involved in the process. The human body is not flayed, but aware of its own flesh. The animal skin lost its flesh while the body in the figure lost its skin. The reader's body becomes sentient in this phenomenon of reciprocity enacted through the differences between the participants.

A visual chiasm is also at work within the image itself. The fleshy figure stands upright, displaying, as the legend says, the villus (fibre) that constitutes the muscles. Conversely, the skin hangs upside down, face down and flaccid. It does not have muscle tone. And while the figure looks toward the text, the flayed skin does not have eyes, as Jack Hartnell points out, just eye sockets that face the viewer directly. The figure's hands are raised while the flayed hands hang limply. ${ }^{35}$ The feet point in opposite directions. The figure still has a discernible human body, comprising nipples and belly button, but the skin only presents a flat empty surface. Emphasising the differences between the two parts, namely skin and flesh, this chiasm creates a tension and brings forward in the image what is under the flesh, on yet another internal layer. This idea of a common overarching flesh emerges here from such a chiasm 
that involves the beholding of an image of the fleshy body touching itself while the readers physically touch a skin like their own.

In line with his description of the chiasm, Merleau-Ponty says that 'art', and by extension visuality, can only emerge from the human body and its 'intertwining of vision and movement'. ${ }^{36}$ The moving body allows humans to participate in the visible world that surrounds them. The body visually exists because it is a body that moves: 'A human body is present when, between seeing and visible, between touching and touched, between one eye and the other, between the hand and the hand a kind of crossover is made'. ${ }^{37}$ Similarly, the flayed figure in the Cambridge manuscript becomes the flesh of the page through this emergent chiasm between the beholder and the page. The figure is pushing its way into the text, creating its own space within the page. Wandering unframed, it is part of the page on the same level as text. Nonetheless, the figure is transient, in flux. An important part of this tension inhabiting the image emerges from the staff. It is reminiscent of pilgrimage, the crucial endeavour of travelling to a holy place for spiritual or medical purposes. It is univocally invoking an idea of physical and metaphorical movement, of walking forward, of passage, of metamorphosis.

The flesh of the image is made visible in the figure's virtual movement. Chauliac explains that one function of muscular flesh is to provide voluntary and involuntary movements. This movement is inherent to the Cambridge figure, which is in a state of transition, neither standing nor advancing, although its whole body seems to be moving by the way it is represented. The legs and face point visibly in the direction of the text, while the torso and hands face the viewer, making the body adopt an uncannily twisted position. The hand guides the viewers' gaze toward the figure. The hanging skin is so fluid that it seems on the verge of falling from the staff. The flayed figure is still organically connected to its lost skin. The wholeness of the body is not scattered, rather it is divided. The figure hints that visibility emerges in the unity of its parts.

Viewers move their eyes between text and image. Vision, through the movement of the eyes, is directed toward the image and further moves between it and the text it is embedded in, between flayed figure and hanging skin. Equally, the viewer moves across the flesh of the page. The figure, reader and page - all elements in this chiasm — visually inform the viewers' relationship to the text. The chiasm and movement create a 
common flesh between the three elements that says to viewers that this is about them. It is their flesh and they can visualise it. The image thereby has a similar function to the skin in relation to the page and is part of its fleshy dynamic. The image is potential, fluidly filling the space. The image is the flesh of the page.

\section{Conclusion}

Mondeville's approach to images is to offer that which is internal to external scrutiny. The viewer of the Cambridge copy of the Chirurgia, who would want to understand the internal functioning of the human body, would see their own flesh according to the flayed figure. They would see themselves as this moving body that is visible. The Cambridge flayed figure conveys something to the beholder's body because, as in 'incarnatyf' medicine, it has become a flesh that fills in a void, an extension. Flesh is the surface of what is visible but only exists insofar as it points toward what is invisible. The spatiality of the drawing is not located in its place on the page, but rather in this state of chiasmic exchange with the text, toward which it is walking, and with the body of the beholder. Its spatiality lies within the movement and fluidity of the flesh. The hand of the figure touching the torso corresponds to Merleau-Ponty's notion of the chiasm and common flesh, coming together in the sensual experience of the figure. The hand connects viewer and image. Flesh is sensing, experiencing itself. The Cambridge flayed figure thus makes flesh emerge from the image and text in this chiasmic exchange. Although this article has focused on a single representation, I hope this close study will open new questions about the fleshiness of images in late medieval Western culture. I believe that a different image theory can emerge from taking flesh, the very defining element of Christianity, into consideration.

\section{Notes}

I wish to thank Robert Mills and the members of the Early Career Research Forum at King's College London for their precious comments on earlier drafts, as well as Jacqueline Jung and William MacLehose for very stimulating conversations at the inception of the project. I am also grateful to the anonymous peer reviewers of Object who provided very helpful advice throughout the editing process. Finally, I would like to thank the Master and 


\section{Fellows of Trinity College Cambridge for granting permission to reproduce} the illustrations.

I 'Quarta figura hominis excoriati portans cutem / suam super humeros per baculum in qua apparet cutis / capitis capillata et cutis manuum et pedu $m$ in qua / apparet caro lacertosa per corpus et glandulosa alba in mam- / millis et emoptoriis(?) per fissuram ventris pinguedo ad- / eps et axungia'. My transcription; translation in Jack Hartnell, 'Tools of the Puncture: Skin, Knife, Bone, Hand', in Larissa Tracy (ed.), Flaying in the Pre-Modern World. Practice and Representation, Cambridge, 20I7, pp. 20-50, p. 22.

This type of figure is traditionally referred to as a 'flayed man'. Mondeville's original Latin 'figura hominis', can be translated as 'the figure of a man/human being'. The medical body in the late Middle Ages is, indeed, typically male. However, in this article, I have decided to refer to the drawing as 'the flayed figure' and have opted for gender-neutral pronouns to describe it. I will, of course, not modify other scholars' translations or phrasing.

2 The text bound in Cambridge, Trinity College, MS O.2.44 is the Anatomia, the first chapter of the Chirurgia.

The various treatises of MS O.2.44 are foliated individually. The flayed figure discussed here is therefore on the fourth folio of Mondeville's anatomy and not on the fourth folio of the manuscript itself.

3 Transubstantiation is the doctrine regarding the change of substance happening during Mass, when during the Eucharist, the bread is changed into Christ's body and the wine into his blood.

4 Henri de Lubac, Catholicism: Christ and the Common Destiny of Man, (trans) Lancelot C. Sheppard and Sister Elizabeth Englund, San Francisco, I988, p. 30.

5 Suzannah Biernoff, Sight and Embodiment in the Middle Ages, Basingstoke, 2002, pp. 5 , 86, I67, I96-I97 and 'Carnal Relations: Embodied Sight in Merleau-Ponty, Roger Bacon and St Francis', in Journal of Visual Culture, vol. 4, no. I, 2005, pp. 39-52. See also Suzanne Lewis, Reading Images: Narrative Discourse and Reception in the ThirteenthCentury Illuminated Apocalypse, Cambridge, I995, p. 9.

6 Maurice Merleau-Ponty, 'The Intertwining - The Chiasm', in Ted Toadvine and Leonard Lawlor (eds), The Merleau-Ponty Reader, Evanston, 2007, pp. 393-4I3.

7 Maurice Merleau-Ponty, The Visible and the Invisible, (trans.) A. Lingis, Evanston, I968, p. I39.

8 French edition and translation in E. Nicaise (ed.), Chirurgie de maitre Henri de Mondeville, chirurgien de Philippe le Bel, roi de France, composée de 1306 à 1320, Paris, I 893. Latin edition in J. Pagel (ed.), Die Chirurgie Des Heinrich von Mondeville (Hermondaville): Nach Berliner, Erfurter Und Pariser Codices, Berlin, I 892. English translations are mine.

9 Loren C. MacKinney has discussed the importance of these images in the development of western anatomy as well as their primacy in early scholarship. Loren C. MacKinney, 'The Beginnings of Western Scientific Anatomy: New Evidence and a Revision in Interpretation of Mondeville's Role', in Medical History vol. 6, no. 3, I962, pp. $233-39$. 
I I See for example the work of Miri Rubin, Corpus Christi: The Eucharist in Late Medieval Culture, Cambridge, I99I or Caroline Walker Bynum, Holy Feast and Holy Fast: The Religious Significance of Food to Medieval Women, Berkeley, 1987; Fragmentation and Redemption: Essays on Gender and the Human Body in Medieval Religion, New York, I99I; Wonderful Blood: Theology and Practice in Late Medieval Northern Germany and Beyond, Philadelphia, 2006.

I2 Marie-Christine Pouchelle, Corps et chirurgie à l'apogée du Moyen Âge, Paris, I 983 published in English as The Body and Surgery in the Middle Ages, (trans.) Rosemary Morris, Cambridge, I990.

I3 MacKinney, op. cit., p.255.

I4 Monica H. Green, 'Introduction', in Linda Kalof (ed.), A Cultural History of the Human Body in the Middle Ages, London and New York, 20I5, pp. I-I6, p. 7.

I5 Ibid., p. 6.

I6 Hans Belting, An Anthropology of Images: Picture, Medium, Body, (trans.) Thomas Dunlap, Princeton and Oxford, 20 I I, p. 37. My thanks to Sarah Salih for this reference. She explores some of these issues in a forthcoming article on Affect Machines.

I7 Ibid., p. Io.

I8 Gabriel Josipovici, The World and the Book: A Study of Modern Fiction, 2nd ed., London, I979, p. 29.

I9 Maurice Merleau-Ponty, L'CEil et l'esprit, Paris, I96I. Published in English as 'Eye and Mind', in Toadvine and Lawlor, op. cit., pp. $35 \mathrm{I}-78$.

20 Lubac, op. cit., p. 30.

2 I Hartnell, op. cit., p. 22.

22 Lard (axungia) is a substance similar to fat (pinguedo) and the adipose panicle (adeps). The difference is that lard is separated from the flesh because it is internal. Mondeville specifies that lard encloses the kidneys and bowels while fat is intertwined with flesh.

23 The Middle French legend of the flayed figure in Paris, BnF MS français 2030 refers to the skin as 'cuir' or leather.

Anne Grondeux, through her analysis of the Latin words cutis and pellis, has demonstrated that there is no fundamental differences between human and animal skin in the Middle Ages. See Anne Grondeux, 'Cutis Ou Pellis: Les Dénominations Médiolatines de La Peau Humaine', in Micrologus: Natura, Scienze e Società Medievali. Nature, Sciences and Medieval Societies I3 (2005): I I3-I 30. 'membrum consimile simplex non spermaticum'.

25 Nicaise, op. cit., p. I7.

26 The Major Surgery of Guy de Chauliac Surgeon and Master in Medicine of the University of Montpellier: Written in 1363, Here Re-Edited and Collated from Latin and French Editions and Complemented with Illustrations; Supplemented with Notes and an Historical Introduction about the Middle Ages and the Life and the Works of Guy de Chauliac, by E. Nicaise, Paris, 189o, (trans.) Leonard D. Rosenman, San Fransisco, 2007, p. I39.

27 Nicaise, op. cit., p. 22.

28 'fulfille De voide placis of smale lymes to brynge hem [them] to a good schap'. Robert von Fleischhacker (ed.), Lanfrank's 'Science of Cirurgie', London, I894, pp. 27-8.

29 Katie L. Walter, 'Fragments for a Medieval Theory of Prosthesis', in Textual Practice vol. 30, no. 7, 2016, pp. I345-63. 
30 Ibid., p. I346.

3 I Nicaise, op. cit., pp. 250, 256.

32 Dominique Poirel, 'Lire l'univers visible : le sens d'une métaphore chez Hugues de Saint-Victor', in Revue des sciences philosophiques et théologiques vol. 95, no. 2, 20I I, p. 374 .

33 Nicaise, op. cit., p. I3.

34 Merleau-Ponty exploits the two meanings of chiasm, as both anatomical structure and literary figure of speech.

35 Jack Hartnell, Medieval Bodies: Life, Death and Art in the Middle Ages, London, 2018, p. $8 \mathrm{I}$.

36 Merleau-Ponty, 'Eye and Mind', op. cit., p. 353.

37 Ibid., p. 355 . 